\title{
In Memory of Gennadi Henkin
}

\author{
Misha Gromov ${ }^{1}$
}

Received: 9 June 2017 / Published online: 11 June 2018

(C) Mathematica Josephina, Inc. 2018

Light was radiating from his face - the Brilliance of his intellect behind the soft glow of kindness in his eyes.

His was a powerful mind open to all kind of ideas and problems in mathematics and also, which is unusual even among the best of mathematicians, he deeply understood science. And he was a charmingly humble person, the word "arrogance" evaporated in his presence.

Many will follow the traces he left in mathematics and his friends will keep the warmth of his personality in their hearts.

Misha Gromov

gromov@ihes.fr

1 IHES, Bures-sur-Yvette, France 